\title{
LOS COMBATES DE VASILI GROSSMAN EL MENSAJE HUMANISTA DE VIDA Y DESTINO
}

\author{
VASILI GROSSMAN'S COMBATS. THE HUMANIST MESSAGE \\ OF LIFE AND FATE.
}

\author{
Luis Miguel Arroyo Arrayás \\ Universidad de Huelva (España)
}

Recibido: 20-05-2012

Aceptado: 26-06-2012

Resumen: En la larga tradición de las relaciones entre filosofía y literatura, la obra de Vasili Grossman es uno de los hitos recientes y más merecedores de atención. Su novela Vida y destino constituye un verdadero manifiesto de confianza en el ser humano, confianza que este merece incluso cuando se ve obligado a existir en condiciones infernales. No solo por este motivo es un texto humanista; lo es también porque contiene una verdadera meditación sobre la condición humana. Tras la catástrofe de las guerras en el siglo XX se ha abierto paso en Occidente un pensamiento de fondo nihilista que tiende a poner en solfa el entusiasmo de los humanismos clásicos, su exaltación del sujeto humano y de la libertad. Sin embargo, una convicción recorre lo más profundo de nuestro ser: a pesar de todo, a pesar de la barbarie y de sus propios fracasos, el ser humano puede elegir entre el bien y el mal, puede decir no, ser él mismo y conservar su dignidad de hombre, de persona única, irrepetible. Sobre esta convicción se asienta la denuncia de Vasili Grossman contra el totalitarismo y contra cualquier intento de anular al ser humano como persona, así como su convicción de que la vida (incluso la vida meramente biológica) se afirma como libertad frente al totalitarismo materialista.

Palabras-clave: V. Grossman, libertad, dignidad humana, humanismo, totalitarismo, culpa.

\begin{abstract}
In the long tradition of the relationship between philosophy and literature, the work of Vasili Grossman is one of the recent and most deserving of attention landmark. His novel Life and Fate is a real manifesto of faith in human being, that it deserves even when it's forced to exist in hellish conditions. Not only for this reason is an humanist text, it is also because it contains a true meditation on the human condition. After the catastrophe of the wars in the 20 th
\end{abstract}


century, has progress in the West a nihilistic thought that puts into question the classical humanisms's enthusiasm, his exaltation of the human subject and freedom. However, a conviction keep in the deepest of our inner: in spite of that, despite the cruelty of their own failures, human being can choose between good and evil, it can say not, be itself and keep its dignity of man, of person unique and unrepeteable. About this conviction, Vasili Grossman's complaint is maintained against totalitarianism and any attempt to override the human being as a person, likewise his conviction that life (even the only biological life) is affirmed as freedom in the opposite of materialist totalitarianism.

Key-words: V. Grossman, freedom, human dignity, humanism, totalitarianism, fault.

Por qué un libro puede conmover hasta lo más hondo al lector es asunto de difícil, por no decir imposible, respuesta. Pero eso es justamente lo que sucede cuando el lector se sumerge en las páginas de Vida y destino, la extraordinaria novela de Vasili Grossman, que con justicia ha sido llamada la "Guerra y $p a z$ del siglo XX", aquel hito de la literatura rusa del siglo XIX nacido del genio de L. Tolstoi. Sin embargo no es mi intención insistir aquí en una comparación entre ambas novelas, sino mostrar algunos de los motivos por los que Vida y destino puede ser considerada un verdadero manifiesto de confianza en el ser humano, confianza que este merece incluso cuando se ve obligado a existir en condiciones infernales.

\section{Vasili Grossman. Breve noticia biográfica²}

Vasili Grossman nació el 12 de diciembre de 1905 en Berdíchev, Ucrania, de padres judíos que se separaron al poco de nacer él. Estudió Química en la Universidad de Moscú y, finalizados estos estudios en 1929, trabajó como inspector en las minas de carbón del Donbass, la gran cuenca minera de Ucrania. Su vocación literaria ya se había manifestado de forma incipiente durante su estancia en la Universidad, pero no fue hasta el año 1934 cuando publicó sus primeros relatos, entre ellos el titulado En el pueblo de Berdíchev, y la novela ¡Buena suerte! Así Grossman decidió dedicarse por completo a la literatura. Sus artículos y relatos le valieron para ingresar muy pronto en la Unión de Escritores Soviéticos y Grossman se convierte -aunque sin llegar nunca a ser miembro del PCUS- en un leal escritor del régimen comunista, encarnando en sus obras los temas y los personajes que eran tan queridos para el realismo socialista: obreros y campesinos entregados a la causa revolucionaria. De este

[1] Cfr. el epílogo de J. Hellbeck a la edición alemana de Vida y destino, Leben und Schiksal: "Krieg und Frieden im 20. Jahrhundert, Claasen, Berlin, 2007, pp. 1069-1085.

[2] Una completa y documentada biografía de Grossman es la de J y C. Garrard: La vida y el destino de Vasili Grossman. Trad. de L. Sanz, Encuentro, Madrid, 2010.

THÉMATA. Revista de Filosofía, №48 julio-diciembre (2013) pp.: 111-120

doi: 10.12795/themata.2013.i48.09 
tiempo data su novela Stepán Kolchuguin -que fue nominada para el premio Stalin- y una obra de teatro: A juzgar por los pitagóricos.

Grossman disfrutaba por entonces de los muchos privilegios reservados a los intelectuales afectos al régimen soviético, pero vivía en un tiempo incierto y terrible. En efecto, en la segunda mitad de los años 30, y en especial entre 1936 y 1938, tiene lugar la llamada Gran Purga. Cientos de miles de personas -trabajadores, campesinos, intelectuales e incluso miembros del Partido- son arrestadas, deportadas a campos de trabajo y muchas de ellas ejecutadas, en una gigantesca campaña de represión para eliminar a los posibles o supuestos enemigos de Stalin. Algunos amigos y familiares de Grossman son detenidos y condenados. Eran ciertamente tiempos en los que los hombres vivían sometidos al miedo y a una cotidiana incertidumbre acerca del destino de sus vidas. De estos terribles conflictos entre el miedo y las exigencias de la conciencia, entre la sumisión a la arbitrariedad del poder y el ansia humana de libertad, dan testimonio algunas de las páginas más extraordinarias, vibrantes y lúcidas de Vida y destino.

En 1941 la Wehrmacht invade la Unión Soviética. La guerra supuso un alivio en la campaña de terror comunista, pues Stalin necesitaba concentrar todas las fuerzas y energías sociales en el esfuerzo bélico. Grossman, que estaba exento del servicio militar por enfermedad, se convirtió en corresponsal de guerra para Estrella Roja, el periódico del Ejército Rojo. Sus crónicas, desde Stalingrado hasta Berlín ${ }^{3}$, tuvieron un enorme éxito popular y sus apuntes del frente le sirvieron para construir la trama de Vida y destino ${ }^{4}$. Por ese tiempo (1943) escribe también con gran éxito un relato largo, El pueblo es inmortal.

En esta época, en la que Grossman pudo aliviar con buenas dosis de entusiasmo patriótico sus propios conflictos internos experimentados por los atropellos y la crueldad stalinista durante la Gran Purga, tuvo el escritor que enfrentarse de nuevo con la angustia e incluso el remordimiento por la incertidumbre sobre la suerte de su madre, Yekaterina Savelievna. En 1944 pudo finalmente averiguar que su madre, había sido ejecutada por los alemanes, junto con otros miles de judíos, en 1941. Podemos representarnos el conflicto y el dolor que todo ello causó en el escritor leyendo en Vida y destino la carta que Víktor Shtrum (uno de los protagonistas) recibe de su madre como despedida ante su inminente ejecución. La madre real de Grossman nunca escribió semejante carta; el escritor la imaginó y constituye uno de los capítulos más impresionantes y emotivos de Vida y destino ${ }^{5}$.

[3] V. Grossmann: Años de guerra, Galaxia Gutenberg - Círculo de Lectores, Barcelona, 2009.

[4] Los apuntes recogidos por Grossman durante la Segunda Guerra Mundial los conocemos gracias a la edición de Antony Beevor y L. Vinogradova: Un escritor en guerra. Vasili Grossman en el Ejército Rojo, 1941-1945. Trad. de J. Madariaga, Crítica, Barcelona, 2006.

[5] Vida y destino. Trad. de M. Rebón, Galaxia Gutenberg - Círculo de Lectores, Barcelona, 2007, pp. 94-110. En adelante me refiero a ella indicando el número de las páginas entre paréntesis.

THÉMATA. Revista de Filosofía, $\mathrm{N}^{\circ} 48$ julio-diciembre (2013) pp.: 111-120 doi: 10.12795/themata.2013.i48.09 
Tras la Guerra, en 1952, publica Grossman Por una causa justa, novela planteada como la primera de dos consecutivas; la segunda sería Vida y destino. Pero Vasili Grossman empezaba a tener problemas con sus publicaciones, que no acababan de ajustarse a las directrices propagandísticas de los jerarcas del Partido. En 1953 muere Stalin y Grossman cree que los vientos de libertad empiezan a soplar en la Unión Soviética. Estaba equivocado. Pero acomete por ello la redacción de Todo fluye, una novela que cuenta el reencuentro con la vida de uno de los cientos de miles de perseguidos por Stalin que, a su vuelta del Gulag, comprueba la magnitud de la tragedia que han supuesto los años de férrea y cruel dictadura.

Entre 1959 y 1960 había terminado Vida y destino. Convencido de que las condiciones políticas eran favorables, Grossman entrega el manuscrito a sus editores, quienes, asustados por el contenido del libro, avisaron a las autoridades. En 1961 el KGB registra el apartamento de Grossman y requisa las copias de la novela. Afortunadamente el escritor había entregado dos copias a sendos amigos de confianza, Semyon Lipkin y Lyolya Dominikina, quienes salvaron el manuscrito ${ }^{6}$.

Abatido por la prohibición de su novela, Grossman cayó en una depresión, aunque logró reponerse y escribió aún algunos relatos, entre los que destaca La paz esté con vosotros. Habiendo enfermado de cáncer, Grossman murió el 14 de septiembre de 1964, convencido de que sus obras más queridas no verían nunca la luz.

\section{Vida y destino: Una declaración de confianza en el hombre en medio de la barbarie.}

En medio de la destrucción, tras la batalla de Stalingrado, Aleksandra Sháposnikova, uno de los personajes de la novela, repasa su vida, golpeada por la barbarie de la guerra y también por la crueldad del stalinismo. Las víctimas de su propia familia yacen por doquier: sacrificadas en las trincheras del combate contra el nazismo y sacrificadas en las siniestras cárceles del Estado soviético como consecuencia de la arbitrariedad. Y ahí está ella, ante las ruinas de su casa, pensando que en una época tan terrible el ser humano no es ya forjador de su propia felicidad. Sin embargo, en medio de la desolación, un pensamiento no le abandona, el pensamiento de que "ni el destino ni la histo-

[6] Algunos años después de la muerte de Grossman, Semyon Lipkin pudo hacer llegar los manuscritos de Vida y destino y de Todo fluye a manos del físico disidente Andrei Sajarov, quien los microfilmó y consiguió pasarlos a Occidente. Sobre las vicisitudes de la novela, véase W. Woinowitsch: "Leben und Schicksal des Wasili Grossman und seines Romans", en Leben und Schicksal, op. cit, pp. 1059-1068. Todo fluye se publicó en 1970 y Vida y destino en 1980, en Suiza. En Rusia no apareció hasta 1988.

THÉMATA. Revista de Filosofía, Nº $^{\circ} 8$ julio-diciembre (2013) pp.: 111-120 doi: 10.12795/themata.2013.i48.09 
ria ni la ira del Estado ni la gloria o la infamia de la batalla tienen poder para transformar a los que llevan por nombre seres humanos" (p. 1093).

Vida y destino es una novela humanista. Tras la catástrofe de la guerra se ha abierto paso en Occidente un pensamiento de fondo nihilista que tiende a poner en solfa el entusiasmo de los humanismos clásicos, su exaltación del sujeto humano y de la libertad. Bien está el servicio crítico que este llamado antihumanismo nos puede prestar. Sin embargo, una convicción recorre lo más profundo de nuestro ser: a pesar de todo, a pesar de la barbarie, el ser humano puede elegir entre el bien y el mal, puede decir no, ser él mismo y conservar su dignidad de hombre, de persona única, irrepetible. Sobre esta convicción se asienta la denuncia de Vasili Grossman contra la barbarie del totalitarismo, tal como puede leerse ya en la primera página de Vida y destino, tras la descripción de la perfecta arquitectura, destructora y alienante, eficazmente inhumana de un campo de concentración: "La vida se extingue allí donde existe el empeño de borrar las diferencias y las particularidades por la vía de la violencia" (pp. 11s).

En efecto, la novela de Grossman es una apasionada y apasionante denuncia de la barbarie de todos los totalitarismos (del nazi y del comunista), unidos ambos en su empeño por someter al ser humano; es decir, por anularlo como persona. Pero es también la narración (con abundantes elementos históricos y autobiográficos) de la lucha del hombre contra esas poderosas fuerzas que quieren arrebatarle su libertad y su identidad personal. La cuestión es, pues, si triunfa la violencia totalitaria y el hombre, sometiéndose, deja de ser lo que es, o si, permaneciendo en su naturaleza libre y en su necesidad de ser él mismo, vence la alienación que produce el estado totalitario.

La novela -monumental- se desarrolla en dieciocho escenarios diferentes, unidos todos por el hilo conductor de la Segunda Guerra Mundial y, en concreto, por la decisiva batalla de Staligrando. Son escenarios en los que se ponen de manifiesto las angustias y las esperanzas de sus diferentes protagonistas, desde los miembros de la familia Sháposnikov hasta los prisioneros del campo de concentración nazi y los detenidos en la temible prisión de Lubianka, en el Kremlin, pasando por los frentes de batalla en los que el Ejército Rojo se enfrentaba a la Wehrmacht.

Ante la imposibilidad de reflejar aquí toda la complejidad y profundidad de la novela de Grossman, voy a fijar mi atención en uno de los personajes, en el que se concentran los esfuerzos, las contradicciones y las claudicaciones, pero también las esperanzas de los seres humanos en su lucha por la libertad y la autenticidad. 


\section{Víktor Shtrum o el combate entre la culpa, la libertad y la sumisión.}

El personaje de Víktor Shtrum es un trasunto del propio Vasili Grossman: ambos tienen una formación científica, ambos son judíos asimilados que toman conciencia de su identidad por el sufrimiento, y ambos comparten la historia trágica de la madre; los dos tienen remordimientos por esa causa, y los dos tienen conflictos con el Estado por su ansia de libertad y por las exigencias -no siempre atendidas- de la conciencia.

El primer rasgo humano que salta a la vista en el personaje de Shtrum es la experiencia de la culpa y la búsqueda de una reconciliación consigo mismo como única posibilidad de liberación. Como ya indiqué, la madre de Grossman fue asesinada por los nazis en Berdíchev (Ucrania). Grossman quería haberla llevado con él a su casa de Moscú, pero su mujer se opuso y el escritor no tuvo el valor -a pesar del peligro inminente- de contradecir a su esposa. El sentimiento de culpa le acompañó el resto de su vida. Entre sus papeles se encontraron dos cartas que él escribió en 1950 y 1961 a su madre muerta, a modo de confesión y de desahogo ${ }^{7}$.

Esta terrible experiencia la llevó Grossman a Vida y destino. Víktor Shtrum repite la propia historia de Grossman y los mismos sentimientos: en medio de su felicidad, basada en el cultivo entusiasta de la física y en la vida cómoda que le deparaba ser un científico reconocido y amparado por el régimen stalinista, Shtrum "se sentía acechado por la duda, el sufrimiento, la desesperación" (p. 93). La carta que su madre le escribió a modo de despedida, sabiendo el destino que le esperaba en el gueto judío de Kiev, sin contener un solo reproche para su hijo, era, sin embargo, el permanente recordatorio de que él, el gran físico había sido un cobarde, pues no había sido capaz de enfrentarse a su mujer, que se había opuesto a que su suegra viviera en la misma casa de Moscú. La carta es también, y sobre todo, una meditación sobre el ser humano cuando se las tiene que ver con un sufrimiento que le desborda. En esas circunstancias terribles se muestran la miseria y la grandeza del hombre, en cuyo interior no funciona ni la lógica ni la brillantez de la física cuántica, sino las leyes del odio y del amor, de la codicia y de la generosidad, de la cobardía y del valor; en definitiva, las leyes contradictorias y misteriosas de la condición humana: "El siglo de Einstein y Planck había resultado ser el siglo de Hitler. La Gestapo y el renacimiento científico eran hijos de una misma época... Había momentos en que la ciencia se presentaba como un engaño que enmascaraba la locura y la crueldad de la vida... Sacó de la mesa la carta de su madre y la releyó... Y una vez más sintió una cuchilla fría golpearle en la garganta" (pp. 110-112). En efecto, la lectura de esa carta (pp. 94-110) deja en el lector un sentimien-

[7] Estas cartas a su madre pueden leerse en T. Todorov, V. Grossman y E. Etkind: Sobre Vida y destino. Trad. de M. Rebón, Galaxia Gutenberg - Círculo de Lectores, Barcelona, 2008.

THÉMATA. Revista de Filosofía, $\mathrm{N}^{\circ} 48$ julio-diciembre (2013) pp.: 111-120

doi: 10.12795/themata.2013.i48.09 
to sobrecogedor, una pregunta radical acerca de la condición humana, capaz al mismo tiempo de hundirse en la vileza y resurgir en la dignidad.

Pero Shtrum no tenía que vérselas solo con su culpabilidad. Su conflicto consistía también en la lucha por la imprescindible libertad científica e ideológica ante el intento del totalitarismo por someter a su soberanía absoluta todos los ámbitos de la vida humana, incluido el de la actividad científica. No solo las artes -que debían obedecer a los criterios del realismo socialista- sino también las distintas ciencias experimentales tenían que ajustarse a la metafísica del materialismo histórico y dialéctico so pena de ser acusadas de "desviaciones burguesas" u "occidentales". En efecto, Shtrum acaba de realizar un extraordinario descubrimiento en el campo de la física teórica y atómica, unánimemente reconocido por sus colegas $(719 \mathrm{ss})$. Pero los científicos del Partido no lo ven con buenos ojos y le acusan de proponer teorías físicas "occidentales" que contradicen la filosofía oficial, que valora ante todo las aplicaciones prácticas frente a la mera teoría (725ss). A ello se une su condición de judío y por tanto sospechoso, a la vista de la nueva actitud de Stalin tras haber aprovechado este el efecto propagandístico de su combate contra el antisemitismo nazi (745). La novela narra magistralmente el miedo de Shtrum a la ira del Partido. Tras las acusaciones vertidas contra él en el periódico oficial, el miedo se extiende también a los amigos de Shtrum, quienes dejan de saludarle. Alguno le aconseja hacer lo que todos hacen: "Escriba una carta de arrepentimiento, como Shostakóvich" (854s y 873s).

Shtrum se debate entre la sumisión y la resistencia, pero poco a poco se va abriendo en él (como sucedió al mismo Grossman) la convicción de que la vida se afirma como libertad frente al totalitarismo materialista.

En medio de la angustia y el terror encontramos la reflexión de los personajes sobre sus propios sentimientos en aquel tiempo terrible. Shtrum visita a su amigo y colega Chepizhin, antiguo director del Instituto de Ciencias, cargo del que había sido apartado a causa de su resistencia a investigar en el ámbito de la física nuclear por su potencial destructivo. Shtrum va a desahogarse de su propio miedo y angustia ante la campaña desatada contra él: "Mis amigos y mi mujer me aconsejan que me arrepienta. ¡Debo arrepentirme de tener razón! (...) Mañana decidirán mi suerte en el Consejo Científico. Es decir, mi suerte ya ha sido decidida por la dirección, en el comité del Partido. En el Consejo Científico sólo cumplirán con las formalidades: la voz del pueblo, la reivindicación pública..." (873s). Tras defender el valor de la ciencia independiente por la felicidad que puede aportar a los

[8] Así sucedió, por ejemplo, en el campo de la genética con los procesos contra N. Vavílov y otros eminentes científicos. Por lo que respecta a la física, las sospechas recaían sobre los físicos teóricos y en especial la física cuántica, acusada de "idealista". Cfr. E. Pollock: Stalin and the Soviet Science Wars, Princeton University Press, 2006.

THÉMATA. Revista de Filosofía, Nº48 julio-diciembre (2013) pp.: 111-120 doi: 10.12795/themata.2013.i48.09 
hombres, Chepizhin inicia una reflexión meta-física (en el sentido etimológico del término) en voz alta sobre la libertad como principio fundamental de la vida, una libertad que guía la evolución misma de la vida y que supera ampliamente a la materia inerte. Esta evolución ascendente de la vida libre llevará al hombre a conquistar el puesto hasta ahora reservado a Dios. Shtrum le interrumpe para discrepar de ese entusiasmo humanista y recordarle que mientras ellos hablan el horror de la guerra continúa, como continúa también el sufrimiento y el terror de los prisioneros en los campos de concentración. A la vista de la realidad surge, pues esta inquietante pregunta sobre las servidumbres científicas ante el poder totalitario: este hombre endiosado, "este hombre del futuro ¿superará en su bondad a Cristo? ¡Eso es lo más importante!... ¿No transformará este hombre el mundo entero en un campo de concentración galáctico?" (872-882).

Shtrum tiene preparada su carta de arrepentimiento, pero en el último momento la libertad vence al miedo. En otro evidente rasgo autobiográfico, Grossman hace que esta victoria de la conciencia vaya acompañada de una abierta confesión de culpa por su cobardía en el pasado: la conciencia -proclama Shtrum- "es lo mejor que tiene el hombre... Nuestra principal desgracia es que no vivimos como nos dicta la conciencia. No decimos lo que pensamos... Nosotros callamos cuando en 1937 [se refiere a la Gran Purga o Gran Terror] ejecutaron a millones de inocentes [entre ellos el propio tío de Grossman, el médico David Sherentsis ${ }^{9}$ ] iY los mejores se callaban! Y hubo algunos que dieron ruidosamente su aprobación" (889-890).

Cuando parecía que el destino de Shtrum era el Gulag una simple llamada telefónica de Stalin -quien percibe la importancia y el poder de la física nuclear- salva a Shtrum y cambia su suerte. El texto refleja el sentimiento de estupor y de terror que despertaba la omnipotencia de Stalin: hablar con él significaba ponerse en presencia de quien detentaba un poder total sobre las vidas de los hombres y mujeres del Estado; él era el Estado, él había ocupado el lugar de Dios (965-979).

La llamada de Stalin transforma a Shtrum. Pronto se da cuenta de que su libertad científica tiene, sin embargo, un precio que pagar: comprende que ha perdido la inocencia por su sumisión al poder y por la sumisión de la ciencia a fines terribles (976). Pero Shtrum se acostumbra a los privilegios, a que se atiendan con premura sus peticiones, y pronto se olvida de los perseguidos y justifica a los perseguidores; sin embargo, siente miedo de su libertad (1037-1041). Parece convertirse en un asimilado del régimen, pero conserva el criterio y la conciencia (1041-45). Así se va llenando su

[9] Véase Garrard, op. cit., pp. 183s. David Sherentsis había acogido en su casa a Grossman y a su madre, tras la separación de sus padres, y fue acusado de actividades antisoviéticas (una acusación standard) y ejecutado en 1938. Grossman, en efecto, no hizo nada por intentar ayudar a su antiguo benefactor.

THÉMATA. Revista de Filosofía, №48 julio-diciembre (2013) pp.: 111-120 doi: 10.12795/themata.2013.i48.09 
vida de contradicciones, de manera que resulta evidente que en el tiempo de la desgracia era más noble y verdadero. Por lo demás, el miedo no había desaparecido; el miedo siempre estaba presente, amenazador (1051-53).

Esas contradicciones llegan al paroxismo cuando los jerarcas del Instituto de Física piden a Shtrum que firme una carta infamante en la que se pide un castigo ejemplar contra dos médicos inocentes, a los que el régimen, en su campaña antisemita, acusaba de haber urdido la muerte de M. Gorki. Una vez más Grossman vierte en Vida y destino sus sentimientos de culpabilidad, en un intento de ajustar cuentas consigo mismo, con su propia cobardía. La historia, en efecto, es real: Grossman asistió en 1952 a una reunión en la sede de Pravda en la que se redactó un documento que pedía un castigo severo para los responsables del "complot de las batas blancas". Grossman lo firmó a sabiendas de la inocencia de los acusados ${ }^{10}$. La escena correspondiente de Vida y destino está narrada con un extraordinario dramatismo (1055-1063), como solo puede hacerse a partir de experiencias intensamente vividas. Los antiguos enemigos de Shtrum le consideran ahora uno de los suyos y él también se ha convencido de ello. Con obsequiosa adulación le piden que firme la carta. Shtrum sabe que se trata de una infamia, de un episodio más del terror totalitario y ciego, pero se ha convertido en un hombre dócil al sistema que le protege y tiene miedo de perderlo todo. Podría haberse negado a firmar - pues ahora está bajo la protección del mismo Stalin- pero precisamente por eso ya era un hombre sumiso, ya no tenía fuerzas para intentar mantener limpia su conciencia, ya no tenía fuerzas para vivir humanamente, es decir, para ser libre. Y firmó.

Shtrum (es decir, Grossman) comprendió en seguida el significado profundo de la sumisión al poder totalitario. Había triunfado en sus luchas científicas, pero había perdido la libertad y la honestidad. Antes, en medio de las dificultades y los problemas era más fuerte y libre. Ahora tenía más poder, pero había perdido su libertad interior y la fuerza que le guiaba en sus luchas.

Sin embargo la historia de Shtrum no acaba en el abatimiento y la obscuridad. En Grossman siempre hay un espacio para la confianza en el ser humano: la vergüenza no debe hundir al hombre en la desesperación o en la indiferencia; la culpa puede ser sanadora y activar de nuevo la esperanza. Grossman concluye la historia de Shtrum con una declaración expresa del propósito que guiaría su propia vida, una afirmación de fe en las posibilidades liberadoras del hombre, que están activas incluso en la derrota:

"Vio con claridad que no era demasiado tarde, que todavía tenía fuerzas para levantar la cabeza, para continuar siendo el hijo de su madre. No buscaría consuelo ni justificación. Aquel acto torpe, vil, bajo le serviría

[10] Véase S. Lipkin: Le destin de Vassili Grosmman, L'Âge d'Homme, Lausanne, 1990, p. 40.

THÉMATA. Revista de Filosofía, Nº48 julio-diciembre (2013) pp.: 111-120 doi: 10.12795/themata.2013.i48.09 
de eterno reproche: se acordaría de él noche y día. ¡No, no, no! No se debía aspirar a la proeza para después enorgullecerse y jactarse.

Cada día, cada hora, año tras año, es necesario librar una lucha por el derecho a ser un hombre, ser bueno y puro. Y en esa lucha no deber haber lugar para el orgullo ni la soberbia, solo para la humildad. Y si en un momento terrible llega la hora desesperada, no se debe temer a la muerte, no se debe temer si se quiere seguir siendo un hombre" (1067). 